\title{
A Day in the Life
}

\author{
Anne Fang
}

Received: 28 April 2014 / Accepted: 21 May 2014 / Published online: 5 June 2014

(C) Academic Psychiatry 2014

"Welcome to Thursday, Dr. Fang!" the social worker greets me with a flourish. This little morning ritual is our thing. I beam back at her as I step into our workroom.

"Welcome to Thursday," I echo back. No matter how crazy things get on unit, this is how we start our day. Second thing, get the census and scan to see if I have any new patients from overnight. Before I got far though, the nurse stops me and tells me that my new patient has fainted after the morning blood draw - needle phobia — and hit her face as she went down. I snap into working mode: "Did she lose consciousness?" Yes, but only briefly. "Was it witnessed?" No. She seems fine. "Okay, protocol is to send her to the ED for evaluation." Agreed. "Wait, I don't even know her story." In her early 20s, Borderline went to the Golden Gate Bridge supposedly to take pictures, left a will. "Oh."

Back to my morning routine: Census, pre-round, morning check-ins, and round. It's numbers - how many hours of sleep, what percentage of meals eaten - and meds - compliant versus not, which PRNs did they receive. I move through the charts efficiently, like running through a well-practiced piece of music. My day is routines punctuated by interludes. Sanity with doses of chaos.

$$
* * *
$$

She's late again. Ten minutes late, to every session, if she shows up at all. My first therapy patient is full of resistance, ambivalence. "Your goal is to illuminate the ambivalence," my attending's words glow softly in my mind as I sit in my therapy chair, waiting, waving an imaginary baton with warm light to her lateness.
Finally, she arrives. Twelve minutes late, a syncopated start to our hour. I ask, as I do every session, "So, how are things?"

$* * *$

My pager goes off. It chirps too loudly in the middle of the night. My heart is pounding like a bomb has gone off. I lie in the darkness of the basement call room. It smells like dampness. I fumble around until my hand finds the pager and turns off the sharp sound.

"33333," the extension of the ED glows green on my pager. I reach over to the lamp, turning it on while narrowing my eyes in preparation for its bright light. On my bedside table, a phone, my clipboard with blank piece of paper on top, my Pilot G2 gel ink roller, my keys, badge, and a clean pair of socks. They are laid out and ready to go.

I punch in the number to the ED. I repeat these words verbatim, "Hi, this is Anne Fang from Psychiatry, returning a page."

$* * *$

I click through the admission order set: $5 \mathrm{mg}$, click, PO, click, daily, click; Pause; 10 mg, click, PO, click, QHS, click; Pause. The rhythm keeps me going.

$* * *$

"Welcome to Friday, Dr. Fang!"

"Welcome to Friday!" I'm only here until 8 a.m., post call, the double bar line at the end. Beyond is a 15 min shuttle ride to the train station, $30 \mathrm{~min}$ on the train, and 15 min walk home. Sometimes the day reverberates; sometimes my mind is quiet on the way home.

\footnotetext{
A. Fang $(\bowtie)$

California Pacific Medical Center, San Francisco, CA, USA

e-mail: FangAF@sutterhealth.org
} 